\title{
Jóvenes y productividad: las nuevas formas del trabajo y el problema del desarrollo humano
}

\author{
Óscar Useche Aldana*
}

Resumen: Este artículo plantea un análisis de las transformaciones en el mundo del trabajo que ha traído consigo el modo de producción post-fordista, avivadas por la crisis global del capitalismo, así como por las consecuencias para el empleo y la productividad de la población joven de América Latina. El hecho de que sean la cognición, el lenguaje y la comunicación los más poderosos focos de la producción inmaterial que hoy reconfiguran el paisaje de estas sociedades en tránsito, hace de los jóvenes un sector rápidamente incorporado a los cambios, duramente golpeados por el desbarajuste de la economía de mercado y, a la vez, sujetos de la apertura a nuevas formas de economía social. La capacidad creativa propia de las subjetividades juveniles les asigna un lugar de exploración de los nuevos mundos productivos en donde el desarrollo ya no está referido a procesos económicos, sino a la configuración de nuevas formas de vida.

Palabras clave: jóvenes, productividad, trabajo, desarrollo

\section{Youngsters and productivity: the new shapes of work and the problem of human development}

\begin{abstract}
This article presents an analysis of transformations in the world of work that has brought about the post-Fordist mode of production, fueled by the global crisis of global capitalism, as well as by the consequences for employment and productivity of the young population of Latin America. The fact that cognition, language and communication the most powerful focus of immaterial production that reconfigure today the landscape of these societies in transit, makes youth a sector rapidly incorporated to changes, hardly hit by the disruption of liberal economy and, in turn, subject of openness to new forms of social economy. The creative ability of youth subjectivities gives them a place in the exploration of new productive worlds where development is no longer related to economic processes, but the configuration of new forms of life.
\end{abstract}

Key words: youth, productivity, work, development

Recibido: 17.06.2009

Aceptado: 08.07.2009

$* * *$

Un análisis crítico de las alternativas del desarrollo humano se hace cada vez más urgente en un mundo en que la crisis del capitalismo ha deri-

*Uniminuto, Bogotá, Colombia. Email: oscarusal@gmail.com 
vado en crisis global de sociedad. De particular importancia para comprender sus posibilidades y limitaciones es el examen de las tendencias globales y locales del mundo de la producción y del trabajo e indagar acerca de las potencias transformadoras de las iniciativas productivas que adelanta uno de los sectores sociales más golpeados por el desbarajuste de la economía de mercado $\mathrm{y}$, a la vez, más decisivos en el rumbo que puedan tomar los nuevos proyectos de desarrollo: los jóvenes.

Este artículo es producto de la reflexión sobre las nuevas formas de productividad de los jóvenes en el marco del trabajo de investigación que desarrolló el Grupo "Ciudadanía, Comunidad y Desarrollo” del Centro de Estudios e Investigaciones Humanas y Sociales de Uniminuto que se propuso estudiar los modos emergentes de asociación juvenil para la búsqueda de ingresos económicos y para plantear soluciones creativas, desde experiencias micro-sociales, a las embestidas de la pobreza y la exclusión ${ }^{1}$.

Las iniciativas juveniles ligadas a procesos productivos fueron comprendidas en este estudio en su dimensión de proyectos de vida que abren sendas de afirmación de autonomías, casi siempre con mucho énfasis en el campo de la cultura, ahora desplegada en plena conectividad con los procesos de subjetivación que discurren desde los dispositivos económicos y de comunicación. Estos proyectos entablan relaciones paradójicas en donde, de un lado se encuentra la tremenda potencia productiva de los lenguajes, las formas de apropiación de las nuevas tecnologías, la refundación de la cooperación y la multiplicación de la producción simbólica de los jóvenes. De otro se ubica, la eficacia cooptativa de la industria cultural y del aparato económico en su empresa de convertir buena parte de la producción simbólica juvenil en mercancía y devolverla a los jóvenes como objeto de consumo. Son diferentes líneas de fuerza en medio de las cuales se pone a prueba el poder de resistencia de los jóvenes frente a las estrategias hegemónicas que circulan a través de nuevos tipos de redes, de controles territoriales, de modificaciones profundas de las políticas de seguridad, de la saturación mediática, del manejo de los mercados y de los miedos, que propulsan una sostenida tensión, un clima de crisis perpetua como estrategia de disuasión y de contención de las explosiones sociales, dentro de las que ocupa lugar destacado las interpelaciones de los jóvenes.

La pregunta es por la índole de las fuerzas que están en juego, tanto las provenientes de los procesos de producción global y local que sufren una acelerada transformación, como los que están definidos por las nuevas formas de cooperación social y que anuncian otras posibilidades de libre realización del poder creativo de los jóvenes.

${ }^{1}$ El trabajo de investigación se desarrolló durante 18 meses en el marco del Convenio Uniminuto - Oxfam - Alcaldía Mayor de Bogotá, mediante el seguimiento, acompañamiento y apoyo a 62 grupos de jóvenes que impulsaban igual número de iniciativas productivas. 


\section{Los cambios en los modos de producir}

Las alteraciones en las maneras de producir y en las relaciones ligadas al ámbito del trabajo ha ido aparejada con las conmociones en la configuración y el papel del Estado, así como con las relecturas de la noción de ciudadanía y los sacudimientos de la vetusta arquitectura de los derechos. La crisis social contemporánea ha desbordado la capacidad de contención y control de muchedumbres ahogadas en la pobreza, el desempleo y la exclusión, que se colocan en estado de permanente agitación. Frente a este panorama el discurso y la política de los derechos humanos ya no solo parecen insuficientes sino que se vacían de sentido y llegan a percibirse como carentes de fundamento. Estas fallas estructurales que se hacen evidentes en el sistema, junto a la proliferación de subjetividades de ruptura y de variadas formas de asociacionismo definidas por la autonomía, son las que justamente abren un espectro de condiciones de posibilidad para el surgimiento y expansión de un campo de lo público no- estatal y de una esfera de lo económico no sujeta a las reglas del mercado.

El conocimiento y el lenguaje se han puesto al centro de los nuevos procesos de producción como recursos privilegiados de la transición postfordista del capitalismo y, al mismo tiempo, de la apertura a nuevas formas de economía social; esto hace de los jóvenes un sector rápidamente sintonizado con estos cambios en curso. La versatilidad de los vínculos inter-subjetivos que emergen en el universo de los jóvenes, su plasticidad y capacidad de políglotas en su propia lengua, los convierte en las sondas de un nuevo mundo productivo constituido principalmente por bienes inmateriales y por el intelecto que se moviliza en lógicas transversales y lingüísticas de valor general.

De esta manera el modo de producción es, como dice Virno: "no sólo una configuración económica particular sino un conjunto de formas de vida, una constelación social, antropológica y ética (digo ética, no moral: relativa a las costumbres, usos y hábitos, no al deber-ser”. ${ }^{2}$

De ahí que el problema de lo productivo en los jóvenes hay que entenderlo vinculado a la gestión de estas nuevas formas de producción que ya no se limitan al problema de los mayores o menores índices de rentabilidad del capital, o a las maneras específicas de su circulación y reposición, sino que son, en sentido estricto, producción de sociedad. La sociedad, al ser producida, entraña procesos múltiples, algunos de naturaleza económica, pero sobretodo otros en los que se plasman relaciones de poder y, más allá, elementos de carácter ontológico como los atinentes a la reproducción de valores sociales y culturales. Lo particular de la época actual es la indiferenciación y yuxtaposición de estos distintos planos de la construcción social.

\footnotetext{
${ }^{2}$ Paolo Virno. “Gramática de la multitud”. Ediciones Colihue. Buenos Aires. 2003. Pá gina 41.
} 
Los cambios en las formas de trabajo son las más visibles. El régimen fabril de producción con su concentración de la mano de obra en talleres sometidos a una estricta división del trabajo, con una administración especializada, unas tecnologías de incorporación de las innovaciones y unas regulaciones estrictas para el control de los espacios y tiempos de los trabajadores, está en estado de disolución. Por todos los bordes del sistema fordista se fueron imponiendo vigorosos focos de producción inmaterial: los lenguajes y los afectos; el pensamiento lógico y la comunicación (que se incorporaron, con toda su densidad semántica, como nuevas fuerzas productivas); la interacción y la confianza entre seres humanos. Todos estos factores, antes asignados al ámbito de la cultura y de la vida cotidiana, segmentados de la esfera del trabajo y de la producción, ahora se han transsustanciado en "poiesis" desnuda: producción lingüística, trabajo afectivo, capital social, trabajo intelectual. Paolo Virno resume esta situación así: "Se disolvieron los límites entre la pura actividad intelectual, la acción política y el trabajo (...)El trabajo contemporáneo incorporó muchos rasgos que antes distinguían a la experiencia política. Es decir, la "poiesis” incluyó en sí numerosos aspectos de la praxis” ${ }^{3}$.

Estas formas de trabajo producen, por consiguiente, no solo bienes materiales e inmateriales sino, ante todo, redes sociales y comunicativas, intercambio acelerado de conocimientos, maneras de cooperación inéditas, conectividades desconocidas hasta ahora, comunidades de nuevo tipo que son en buena medida resultado de los intensos procesos de subjetivación que vive el mundo contemporáneo.

El problema es que las convulsiones de este tránsito radical no han destituido a los poderes al mando y la soberanía representada tiende a refugiarse en modelos totalitarios, abandonando muchos de los paradigmas y territorios que dieron vida a la modernidad occidental, optando por discursos simplificadores y vacíos para intentar cargar de sentido fórmulas inertes como la de la omnipotencia del mercado.

Estos son algunos de los contextos para los jóvenes cuando se ven avocados a su vinculación a la vida de la producción material y a las angustias de una práctica laboral para la subsistencia.

\section{Las mutaciones en el mundo del trabajo y su influencia en las iniciativas productivas de los jóvenes}

Enfrentar el reto del trabajo es para los jóvenes de hoy una pregunta integral por el mundo de la vida. Hasta hace poco ese era un ejercicio que tenía mucho de un rito de paso: salir del hogar a la esfera de las necesidades; ingresar (ser incluido) en escenarios delimitados y regulados del trabajo asalariado, constituido como un territorio fraccionado, jerárquico, dis-

${ }^{3}$ Paolo Virno. “Gramática...” Op. Cit. Página 43 
ciplinado y modulado por un ingreso relativamente estable. Significaba una adscripción de clase y una relación de antagonismo con el capital privado, además de fundadas expectativas de ser sujeto de la intervención del Estado como garante de sus derechos y mediador de sus reivindicaciones. En la fábrica el joven devenía adulto y se hacía ciudadano de los de abajo; quedaba inserto en un modo de subjetivación definido por reconocer su ubicación en el espectro social y por darle el boleto de entrada en propiedad a la sociedad de consumo.

El paisaje es ahora otro. La sociedad post- fabril rompió las regulaciones del trabajo, disolvió la disciplina de la fábrica, redefinió la especialización y división del trabajo, flexibilizó la contratación y las condiciones laborales y descentralizó las unidades productivas. La contingencia es el nuevo signo de las relaciones de trabajo; las fronteras entre el empleo y el desempleo se han desdibujado, no solo por la rotación perenne del trabajador entre un empleo y otro, entre un tipo de contrato y otro, sino por la interrupción constante de su vínculo con un empleador a cambio de un salario.

Por períodos cada vez más recurrentes y extensos el antiguo obrero se ve arrojado a esa zona de indiferencia en la que su subsistencia depende solo de su propia potencia de resistencia, de su aptitud para hacer gala de capacidades de transformación de las relaciones familiares, de vecindad y de amistad en redes económicas y de ayuda mutua. Eso significa revalorizar estas relaciones, sacarlas del universo de lo estrictamente privado, a donde estuvieron confinadas, para reconvertirlas en territorios productivos en donde los conceptos clásicos del ingreso económico y del vínculo laboral son reubicados en el contexto de lo comunitario.

Nociones como empleado y desempleado, u otros como empleo por cuenta propia, empresa familiar o micro- empresas se van destiñendo en la medida en que la masa de trabajadores contingentes va siendo reabsorbida por el tejido de proyectos sociales y negociaciones con el Estado, naturalizando la precariedad del ingreso, pero creando las condiciones para el surgimiento de otras formas de cooperación y de trabajo. En medio de ellas se instalan muchas de las iniciativas productivas de los jóvenes que disponen sus proyectos creativos a modo de crisálidas que anuncian el vuelo de nuevas relaciones con lo público y en donde se confunden la intensa experiencia individual con el ensayo de lo colectivo ${ }^{4}$.

\footnotetext{
${ }^{4}$ Marisol, una joven que hace parte de la iniciativa productiva, en entrevista concedida a los investigadores del Ceihs señaló: "Nosotros no estamos operando con el sistema de trabajo tradicional. De entrada, a nivel organizacional del equipo, como sabemos que de algo tenemos que vivir, uno tiene que pensar en el tema de las necesidades ¿entonces como pensamos en el tema de las necesidades? Es como lo estamos haciendo ahora: tenemos una idea de la autogestión”. Entrevista a Marisol Sánchez. Iniciativa Productiva de Microempresa Social "El Rehuso" Banco de Datos. CEIHS. Uniminuto. Bogotá.2008.
} 
Diferentes estudios han indicado que el modelo de desarrollo de la fase post-fordista tiene en su mira garantizar el crecimiento del producto bruto y de los márgenes de rentabilidad, a costa del incremento de la desocupación y la marginalidad de la mayoría de la población; aparte de otras secuelas perversas como el inmenso problema ambiental y alimentario y la exposición permanente de la humanidad a las pandemias y a la guerra. Ahora la solución de las necesidades vitales de la población ha sido cada vez más abandonada por el Estado y el gran capital a la propia suerte de los empobrecidos. Estos dependen con frecuencia de sus propios recursos y de la conectividad de las redes de cooperación y asociación; contando con la circunstancia de que esta confluencia ya no la provee el Estado, sino que se agencia por medio de facultades que les son comunes a todos los seres humanos como el lenguaje y la comunicación. El espacio común que de ahí emana se da en el marco de la constitución de un intelecto general, y sus actos se hacen directamente productivos, al tiempo que la trama de la sociedad se hace más tupida y compleja.

Entonces no se trata simplemente de idear estrategias para enfrentar la pobreza o de luchas por la inclusión en el sistema formalizado de consumo, sino de la creación de fuerzas productivas de naturaleza social que proyectan formas novedosas de comunalidad alimentadas por la diversidad y la capacidad generativa de cambios profundos.

Tal como se reseña en el libro "Los Nuevos Sentidos del Desarrollo: "Muchas de las actividades denominadas "informales" o del rebusque, que atañen a formas de comercio al menudeo, reutilización de bienes, labores vinculadas a la distribución y a la comunicación, pequeñas empresas familiares de alimentación, reciclaje, servicios personales o pequeña agricultura; tienden a organizarse a través de comunidades prácticas, algunas de las cuales rememoran al viejo mutualismo, o retoman los principios y la experiencia del cooperativismo, o le asignan nuevas funciones y ámbitos de trabajo a las organizaciones vecinales, a las asociaciones civiles, a los sindicatos o a la acción eclesial, o simplemente se estructuran como redes de ayuda mutua" ${ }^{5}$.

Los jóvenes descubren rápidamente las claves de esta nueva situación del trabajo; comienzan a entender que al centro de ella está la fuerza de las relaciones de solidaridad y reciprocidad que se han desarrollado tanto desde los vínculos de proximidad (amistad, vecindad), como desde sus incursiones en lo público a través de lo comunitario. Pero también comprenden que se trata de acceder a nuevas formas de conocimiento y que para ello hay que arrancar por desmitificar la especialización productiva que antes definía fronteras de acceso al trabajo, pues se requería presentar credenciales provenientes o de unas habilidades adquiridas en el sistema de formación técnica, o heredados del aprendizaje de un oficio en el ámbi-

${ }^{5}$ Óscar Useche. "Los Nuevos Sentidos del Desarrollo”. Universidad Bolivariana. Santiago. 2008. Páginas 49 y 50. 
to familiar. Ahora son otras las vías: a través de una muy diversa red de formas de organización de las labores productivas, muchas de las cuales las constituyen en relación con sus pares, se adaptan conocimientos, se apropian recursos económicos originados en circuitos de ayuda estatal o de cooperación internacional y se descubren maneras de escapar de mercados muy regulados para proponer nuevas lógicas de intercambio y de consumo. El sentido de la relación económica se impregna entonces de la dimensión de lo social, en todo su espesor, esto es, que el asunto no es la mera acción individual de sobrevivencia, sino la reproducción de la vida del colectivo, con la proyección hacia lo público que esto implica. Los ensayos en busca de salidas al problema de la desocupación y la pobreza se enclavan de esta manera en modos de subjetivación juvenil, colocados en el trayecto de formas nuevas de lo público.

\section{El nuevo entorno de lo común y las iniciativas productivas de los jóvenes}

Como se ha dicho antes, en la fase actual de la sociedad capitalista se está dando una transición productiva que reemplaza la predominancia de la producción industrial de bienes materiales, con base en un modelo de banda de montaje conocido como "fordismo". La etapa posterior a este modelo (el post-fordismo) pone su acento en la creación de bienes inmateriales y reubica dentro de nuevos códigos de reproducción ampliada la esfera de la fabricación de los bienes materiales de consumo. En este modelo emergente el principal valor agregado surge de la capacidad para captar la materia prima esencial de la economía globalizada: el uso de las facultades humanas del pensamiento y del lenguaje, a partir de las cuales los nuevos trabajadores desarrollan su potencia creativa. La espiral productiva de este capitalismo post- industrial se difunde sobre las aptitudes comunicativas e informacionales que se van haciendo comunes a todos y que transmiten no solo las nuevas demandas de consumo de bienes materiales, sino emociones, símbolos, afectos, sensaciones y formas de vida. Este nuevo modo de producción se desarrolla sobre los avances de la revolución científico- técnica de última generación y va consolidándose poco a poco como nueva forma de ser social a partir de multitud de experiencias colectivas que poco a poco van englobando el conjunto de la sociedad.

Los cambios abarcan también asuntos decisivos de la dimensión de lo público en la medida en que el soporte unificador de la sociedad moderna, el Estado, se torna obsoleto en su forma actual y comienza a perder el monopolio de la integración social, cambiando el paisaje de la llamada comunidad nacional, cuyo poder subjetivo y entramado institucional se ven ahuecados y desafiados por múltiples nuevos agentes de lo público que van constituyendo una nueva esfera colectiva, compleja, contradictoria, agonal, pero con dos elementos en común: el debilitamiento del centro de mando indiscutible asignado al Estado -y por ende el resquebrajamiento de la obligación de obediencia inequívoca hacia él- y el nacimiento de formas de 
vida insólitas que ya no están más en la órbita de la relación unívoca trabajo asalariado- capital.

Estas tendencias avanzan con paso firme en países como Colombia, aunque hasta ahora el motor dinamizador ha estado en los países centrales del mundo industrializado. En ese ámbito son diversas y plurales las formas de sociedad y de comunidad que van poblando los territorios, así como incontenibles los espacios sociales que rompen la hegemonía del par mercado-Estado, que, enunciado por el primero, se impuso con visos totalitarios y de ideología única durante el imperio de la globalización neoliberal.

Todo el mundo de la vida se tornó contingente, precario e inestable en esta etapa de la globalización de mercado que fue demoliendo las certezas que contenían y ordenaban la sociedad del capitalismo de masas. Este fenómeno dejó una profunda huella en costumbres e imaginarios, transformó las maneras de ser en sociedad y, de entrada produjo alarmantes signos de angustia colectiva y miedos descontrolados, sobre los que han cabalgado proyectos autoritarios y fundamentalismos del terror. Poblaciones enteras desplazadas pierden su vital arraigo con la tierra y deben reaprender todo del arte de sobrevivir; el saber laboral de muchos trabajadores víctimas de la reingeniería de las empresas se vuelve superfluo. Los jóvenes perciben que para nada es suficiente aprender un oficio determinado; que las virtudes asignadas al esfuerzo educativo como palanca infalible para entrar en las corrientes de la movilidad social, han perdido casi toda su potencia.

Ya no hay verdades que funjan como amarraderos de los escenarios sociales que se reproducían de generación en generación. Pareciera que cada cual debiera construir su pequeña balsa para no naufragar en el océano sin fondo de una sociedad en disolución. No obstante, este ha sido el acicate para que los jóvenes transformen sus frágiles embarcaciones en territorios existenciales flotantes y de gran movilidad.

\section{Los jóvenes y el Intelecto General}

Las aguas agitadas de la producción social por las que navegan nuestros jóvenes se asientan sobre ese gran cerebro social, fundamento de la producción global contemporánea, que se ha ido constituyendo al vaivén de los cambios en el modo de producción: el intelecto general (“General Intellect” como lo llamaba Marx) conformado por las capacidades lingüísticas, comunicativas y de cognición de todos los seres humanos. El pensamiento ya no es esa actividad solitaria reservada a los intelectuales profesionales y a los sabios, ni una actividad íntima y privada de una élite, ahora la actividad de la mente es un bien colectivo, algo así como un intelecto público, construido entre todos, por medio del cual se crea el espacio común entre los productores, es decir un intelecto directamente productivo y con potencia asociativa: un intelec- 
to general poiético ${ }^{6}$. La categoría "intelecto general”, que tanto contribuye a explicar las mutaciones en el trabajo contemporáneo, es uno de los grandes aportes de Marx que habían quedado sepultados por las simplificaciones y las interpretaciones economicistas de las corrientes del marxismo soviético. Los procesos recientes de evolución del modo de producción capitalista corroborarían el carácter social y público que ha adquirido el intelecto y las razones por las que se ha hecho visible su poder creativo en la producción de la riqueza y en el alumbramiento de la sociedad tal como hoy la vivimos.

De ahí que sea importante para esta reflexión detenerse un momento en la exposición que Carlos Marx hace de este problema en las páginas de los "Cuadernos de Grundrisse": "En esta transformación lo que aparece como el pilar fundamental de la producción y de la riqueza no es ni el trabajo inmediato ejecutado por el hombre ni el tiempo que éste trabaja, sino la apropiación de su propia fuerza productiva general, su comprensión de la naturaleza y su dominio de la misma gracias a su existencia como cuerpo social; en una palabra, el desarrollo del individuo social. El robo de tiempo de trabajo ajeno, sobre el cual se funda la riqueza actual, aparece como una base miserable comparado con este fundamento, recién desarrollado, creado por la gran industria misma. Tan pronto como el trabajo en su forma inmediata ha cesado de ser la gran fuente de la riqueza, el tiempo de trabajo deja, y tiene que dejar, de ser su medida y por tanto el valor de cambio [deja de ser la medida] del valor de uso. El plustrabajo de la masa ha dejado de ser condición para el desarrollo de la riqueza social, así como el no-trabajo de unos pocos ha cesado de serlo para el desarrollo de los poderes generales del intelecto humano. Con ello se desploma la producción fundada en el valor de cambio, y al proceso de producción material inmediato se le quita la forma de la necesidad apremiante y el antagonismo. Desarrollo libre de las individualidades, y por ende no reducción del tiempo de trabajo necesario con miras a poner plustrabajo, sino en general reducción del trabajo necesario de la sociedad a un mínimo, al cual corresponde entonces la formación artística, científica, etc., de los individuos gracias al tiempo que se ha vuelto libre y a los medios creados para todos El capital mismo es la contradicción en proceso, [por el hecho de] que tiende a reducir a un mínimo el tiempo de trabajo, mientras que por otra parte pone al tiempo de trabajo como única medida y fuente de la riqueza. Disminuye, pues, el tiempo de trabajo en la forma de tiempo de trabajo necesario, para aumentarlo en la forma del trabajo excedente; pone por tanto, en medida creciente, el trabajo excedente como condición -question de vie et de mort- del necesario. Por un lado despierta a la vida todos los poderes de la ciencia y de la naturaleza, así como de la cooperación y del intercambio social, para hacer que la creación de la riqueza sea (relativamente) independiente del tiempo de trabajo empleado en ella. Por el otro lado se propone medir con el tiempo de trabajo esas gigantescas fuerzas sociales creadas de esta suerte y reducirlas a los límites requeridos para que

\footnotetext{
${ }^{6}$ Poiesis, es un término griego que significa creación.
} 
el valor ya creado se conserve como valor. La naturaleza no construye máquinas, ni locomotoras, ferrocarriles, electric telegraphs, selfacting mules, etc. Son éstos, productos de la industria humana: material natural, transformado en órganos de la voluntad humana sobre la naturaleza o de su actuación en la naturaleza. Son órganos del cerebro humano creados por la mano humana; fuerza objetivada del conocimiento. El desarrollo del capital fixe revela hasta qué punto el conocimiento o knowledge social general se ha convertido en fuerza productiva inmediata, y, por lo tanto, hasta qué punto las condiciones del proceso de la vida social misma han entrado bajo los controles del general intellect y remodeladas conforme al mismo. Hasta qué punto las fuerzas productivas sociales son producidas no sólo en la forma del conocimiento, sino como órganos inmediatos de la práctica social, del proceso vital real?

Excuse el lector esta larga cita, pero en este conocido "fragmento sobre las máquinas”, Marx deja planteadas unas claves de interpretación sobre las modificaciones en las formas de trabajo, que hoy se están materializando y que afectan directamente a los jóvenes. La insistencia sobre el carácter de fuerza productiva general que ha tomado el conocimiento y su papel en la configuración de lo que denomina el "individuo social” aportan gran claridad al fenómeno de la difusión y apropiación general del poder creativo del lenguaje, la comunicación y los saberes. Ello se condensa en el concepto de "intelecto general" que aparece como un campo social determinante, en el que ya no solo las máquinas son "fuerza objetivada del conocimiento", sino que éste, en su forma "pura” de saberes comunes y habilidades comunicativas, es decir, todo lo que Virno llama tramas “de la vida de la mente”, produce inmediatamente formas de valor general.

Las dinámicas en torno a formas lingüísticas y a nuevas lógicas sociales que experimentan nuestros jóvenes ratifican su inmensa fuerza enunciativa, al igual que la capacidad productiva y subjetiva que liberan. Cuando los jóvenes se agrupan recurren, algunos de ellos ponen todo su acento en la especialización lingüística de estos territorios estéticos. Pero esto les sirve solo para entablar procesos de identificación y pertenencia de grupo. Cualquier intercambio con otros jóvenes o con otros miembros de la sociedad les obliga a establecer lazos de lenguaje común, a participar de la creación de "lugares comunes del lenguaje", entendidos como formas genéricas de interlocución; adoptar lógicas lingüísticas transversales que los vinculen al trazado de espacios de encuentro con otros lenguajes especiales, en donde se constituyan tramas de un discurso común. Estas operaciones solo son posibles apelando al “intelecto general”, haciéndose parte de él, generando desde él formas de pensamiento y principios de argumentación que favorezcan puntos visibles de interconexión y recursos cognitivos a disposición de

\footnotetext{
${ }^{7}$ Karl Marx. "Elementos fundamentales para la crítica de la economía política. (Grundrisse) 1857- 1858”. Volumen 2. Siglo XXI Editores. México 2002. Páginas 228- 230.
} 
todos. Este conocimiento abstracto junto a las estructuras más comunes y generales del lenguaje se convierten en los instrumentos más importantes para definir los comportamientos de los jóvenes, para desplegar su potencia vital, para idear sus estrategias de protección, así continúen aferrados a sus quebradizos territorios flotantes. Los jóvenes devienen intelectuales, no porque se dediquen a la lectura, al ejercicio literario, a las ciencias duras o a las artes, sino porque deben echar mano del intelecto general para hacerse jóvenes. Deben hacerse pensadores así no los apasionen los libros, los enunciados filosóficos, ni la ecuaciones matemáticas; solo porque, de manera ineludible, este es el camino tortuoso para vincularse al torrente productivo de la sociedad y para que esa sociedad-que todos los días parece disolverse-, se reconstituya una y otra vez.

Como las comunidades ya no son duraderas y sustanciales, por cuanto la contingencia es el signo de los tiempos y es cada vez más difícil la reproducción sistemática de hábitos, representaciones sociales y memorias culturales, los jóvenes han creado nuevas formas de percepción y de expresión cuya eficacia se sustenta en la capacidad juvenil de saltar de un ensayo a otro, sin fatiga; replicando elementos de lo aprendido en un espacio de experimentación, e incorporando los códigos y aprendizajes del nuevo intento. Tal versatilidad no sería posible sin apelar al intelecto abstracto, que está presente en los lugares comunes de los lenguajes, que surgen de los procesos de subjetivación desencadenados en medio de la lucha entre los poderes dominantes y las fuerzas de la vida. Este intelecto general es, a su vez, punto de partida de nuevas subjetivaciones.

De ahí que el intelecto público pueda transitar caminos muy disímiles. Puede, por ejemplo, ser el coto de captura de pensamientos, aptitudes lingüísticas, capacidades cognitivas, dinámicas de aprendizaje constituidas comúnmente, para ser usados en servicio de fuerzas opresivas que intensifiquen, a partir de él, la sumisión del trabajo. Son muchos los dispositivos de captura que intentan canalizar esta imponente potencia creativa y convertirlos en meros productores de plusvalor al servicio del capital, de la acumulación insaciable, del consumo devastador.

O, puede suscitar construcciones de lo público inéditas, que acentúen la potencia de ser de los humanos, espacios políticos democráticos para que todos aprendan a ocuparse de los asuntos comunales y convertirlos en lugares comunes para la emancipación. Para ello, el "general intelect” de Marx debe devenir en nuevas dimensiones de lo público, en renovadas formas de lo común, en distanciamiento de las soberanías del miedo y de la muerte.

El proceso productivo íntegro se coloca en una de estas dos lógicas e involucra especialmente a los jóvenes que se integran en su búsqueda de trabajo y de realización productiva, como se verá enseguida. 


\section{La integración de los jóvenes a la producción a partir del conocimiento y de sus aptitudes lingüísticas}

Los jóvenes intervienen en el mundo de la producción a partir de sus singularidades y modos de ser, en lucha con las añejas subjetividades del obrero fabril de la fase fordista del capitalismo, así como lejos de inscribirse en las identidades del tipo del empresario clásico.

La capacidad productiva del joven está mucho más cerca de los nuevos procesos de subjetivación post- fordistas, en donde se participa de destrezas y talentos generales en materia de conocimiento, lenguaje y comunicación, sobre los cuales se han instituido las nuevas maneras del hacer laboral. Al respecto Virno señala que: "Todos los trabajadores entran en la producción en cuanto hablantes-pensantes. Nada que ver, digamos, con la "profesionalidad", o con el antiguo "oficio": hablar/pensar son aptitudes genéricas del animal humano, lo contrario de cualquier especialización. Este compartir preliminar (...) es la base misma de la producción actual. Compartir, en tanto requisito técnico, se opone a la división del trabajo, la contradice. Esto no significa, naturalmente, que los trabajos ya no estén divididos, parcelizados, etcétera; significa sobre todo que la segmentación de los trabajos ya no responde a criterios objetivos, "técnicos", sino que es explícitamente arbitraria, reversible, cambiante. Para el capital, lo que verdaderamente cuenta es la originaria y compartida dote lingüístico- cognitiva, dado que ella garantiza adaptabilidad, una rápida aceptación de las innovaciones, etcétera" ${ }^{8}$.

Los jóvenes hacen parte de los nuevos sujetos productivos que han emergido de la fase post-fordista del capitalismo como fruto de la profunda reestructuración a la que éste fue sometido. Al transformar el trabajo, el modo de producción que se impone trae consigo la difusión del intelecto general y el surgimiento de nuevas figuras de cooperación del trabajo vivo, no controladas desde las fábricas, trasmutadas desde el mundo del "ejército industrial de reserva”, es decir desde la masa de desempleados que arroja el propio modelo de producción. Estas figuras, con su inmensa capacidad de producir, son captadas y sometidas por el capital en nuevos escenarios de producción, pero solo de manera parcial, pues como se indica en otro texto del autor de este artículo: "Siempre hay un excedente de potencia productiva, un plus valor social expresado en saberes, en inteligencia colectiva, en nodos de comunicación y capacidades para generar nuevas intersecciones y encuentros, en despliegue de afectividades y solidaridades de donde surge lo común como condición previa, materia prima de otras alternativas de desarrollo, de reconstitución de lo público y, seguramente a la vez, como resultado de esa espiral de procesos innovadores y liberadores. Estamos ante una fuerza inmanente, que ya no se referencia obligatoriamente al capital, que es potencialmente autónoma y en donde la creación de cooperación se convierte en característica y virtud interna del trabajo

${ }^{8}$ Paolo Virno. “Crear una nueva esfera pública sin Estado”. Entrevista por Héctor Pavón. Periódico “El Clarín”. Buenos Aires. 24.12.2004. 
que tiende a producir directamente los medios de interacción, apoyo y comunicación para la producción, formándose como una relación externa al capital, creada en común y abierta a nuevas formas de cooperación. ${ }^{9}$

Hay entonces una paradoja en el modo de producir del post-fordismo, pues, de una parte se potencia hasta niveles impensados la productividad social y, con ello, el fondo del que puede extraer valor el capital; pero de otra parte, esa expansión -que abarca la cultura y la capacidad de cognición y de lenguaje de la sociedad entera, es decir que abarca la vida misma- no puede ser aprehendida totalmente por los mecanismos de reproducción del capital. Sucede que con los cambios técnicos y la rápida obsolescencia de los sistemas centralizados de reproducción capitalista las relaciones entre la esfera de los trabajadores empleados y la de quienes estaban fuera del circuito productivo, asignados al ejército industrial de reserva (desempleados), han variado radicalmente. Hoy las fronteras entre los trabajadores y los no- trabajadores se han debilitado en grado sumo.

Es del trabajo que nace el valor; la apropiación del excedente producido por la fuerza de trabajo ha valorizado permanentemente el capital. Ese es el paradigma explicativo del funcionamiento del capitalismo que Carlos Marx refinó en su teoría del valor. Pero lo que hoy ha cambiado es la naturaleza del trabajo; la producción y la vida se han ido integrando y se han hecho indiferenciadas. Eso mismo ocurre con las esferas del trabajo (formalizado) y el no- trabajo (informal); con el mundo del empleo y el de la creciente masa de los desempleados. La medida del valor producido, mesurada a través del "tiempo de trabajo necesario" que planteó la teoría del valor ha sido interpelada por las nuevas condiciones del trabajo social. La precariedad del contrato laboral; la creciente importancia de los trabajadores a tiempo parcial; la inestabilidad de los vínculos con la fábrica o con la empresa y, sobre todo, el crecimiento de una franja mayoritaria de empleados por cuenta propia, la proliferación de actividades productivas en el hogar o en el entorno comunitario, así como el desarrollo de una infinidad de actividades productivas que no tienen remuneración económica, son solo algunas de las modalidades que trastocan la relación comúnmente asignada entre los espacios y los tiempos del trabajo y los territorios y ritmos de la reproducción de la vida.

Como el trabajo se confunde con la vida, es en éste ámbito (el de la vida integral) en donde hay que buscar la fuente de producción de la riqueza y, por tanto, ésta no se puede circunscribir a los elementos económicos que generalmente la determinaban. No solo lo que se produce en los tiempos de trabajo se integra a la valorización del capital; ahora éste dispone para ello de los procesos de reproducción de la vida y de todas las formas de trabajo no formalizado (no- trabajo) en donde se despliegan capacidades y fuerzas productivas similares a las que se contratan formalmente en

${ }^{9}$ Óscar Useche, et. al. “Desarrollo, ciudadanía y cambio Social”. Uniminuto, DANSOCIAL, Fundación Carolina. Bogotá. 2007. Página 19. 
las empresas. Solo que organizar la vida entera, controlarla política y económicamente, es una función que rebasa la experiencia administrativa obtenida en los circuitos fabriles, mercantiles, institucionales o los adquiridos desde el control del viejo Estado nacional. De ahí que nuevas formas de poder sobre la vida (bio-poder) se abran paso.

\section{Las formas de trabajo y no-trabajo entre los jóvenes de América Latina}

El universo juvenil experimenta a diario esta situación. Se han incrementado las políticas dirigidas a ellos para prepararlos para el trabajo; el discurso de la educación como palanca infalible para encontrar ocupación remunerada y su implementación en políticas para asegurar el derecho a la educación de la mayoría se ha traducido en una población joven alfabetizada, con aptitudes para adaptarse a las tecnologías informáticas avanzadas, en esa misma medida fácilmente incorporables a circuitos globalizados, pero no ha conseguido proveerles empleos remunerados y de calidad. La fase post fordista del capitalismo es productora estructural de desempleo y de empleo precario y las nuevas generaciones de trabajadores son sus principales damnificados.

No se requiere de una particular agudeza crítica para registrar esta situación. Un estudio de la OIT resume el problema de la siguiente manera: "Los jóvenes latinoamericanos constituyen el segmento más numeroso de su población en edad de trabajar. Nacieron en los ochenta, uno de los periodos más críticos de la historia reciente de la región: la llamada “década perdida”. Han crecido en medio de numerosas y grandes transformaciones en el mundo de la producción y del trabajo: globalización de los mercados, migración masiva, mayor requerimiento y uso de tecnologías de información e idiomas y -en algunos países reformas laborales significativas, entre otras. Son más educados que generaciones anteriores. Sus primeros años los vivieron en un contexto de crisis frecuentes y han sido testigos de cómo los mercados laborales de la región se tornaban precarios al mismo ritmo que sus condiciones de vida y las de sus familias. Esto ha llevado a que cuestionen si la educación y el mercado de trabajo son realmente vehículos para el progreso personal y social, lo cual reta a la gobernabilidad democrática. Hay un creciente porcentaje de jóvenes desarraigados y excluidos sin confianza en las instituciones" ${ }^{10}$.

El estudio indica que de los 106 millones de jóvenes entre 15 y 24 años que hay en América Latina, un importante segmento está fuera del sistema escolar, aún estando en edad de estudiar; así mismo, la curva que refleja el número de jóvenes que trabaja se triplica entre los 15 y los 24 años, tal como se observa en la siguiente gráfica:

${ }^{10}$ Oficina Internacional del Trabajo (OIT). Naciones Unidas. “Trabajo decente y juventud”. Lima. 2007. Página 23. 


\section{Gráfica 1 \\ Tendencias de ocupación de la población jóven en América Latina}

\section{América Latina y el Caribe: cambios y decisiones frente a los jóvenes 2005}

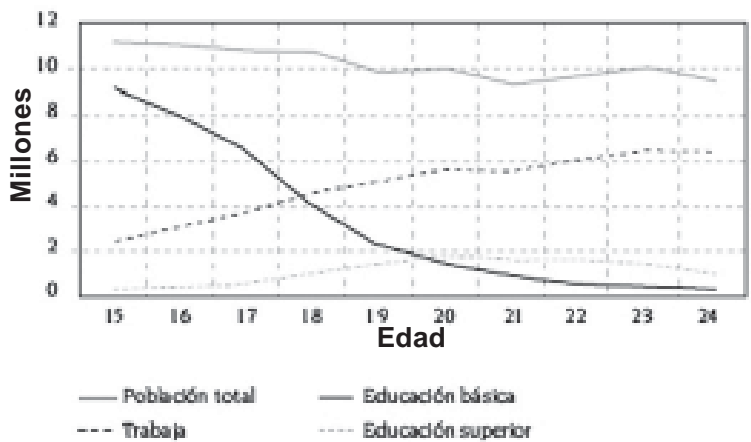

Fuente: Elaboración OIT en base a procesamiento especial de encuesta de hogares.

Del estudio de la OIT se deduce que los jóvenes enfrentan tasas de desempleo mucho mayores que las de los adultos, en una relación de tres a uno; en algunos países de la región esta proporción es aún mayor. Las condiciones de trabajo precario y de informalidad cubren a 30 millones de muchachos de América Latina y el Caribe, mientras que se calcula que 22 millones no estudian ni trabajan. También, señala la investigación de la OIT, Los índices de desempleo de los jóvenes en el 2005 son mayores en promedio a los existentes en 1990. Esta tendencia a la intensificación del desempleo juvenil se ha acentuado en los últimos años y se hará aún más grave en la medida en que se sientan en la región los efectos de la crisis financiera y económica internacional del año 2008 que además incrementa la precariedad en los mercados laborales. Téngase en cuenta que el empleo de mala calidad ya afecta a uno de cada dos trabajadores de América Latina y que entre los jóvenes se calcula que involucra a las dos terceras partes. La descripción que hace el estudio de la OIT, le pone cifras concretas: "De los 106 millones de jóvenes en América Latina y el Caribe, en 2005, 48 millones se encontraban trabajando en tanto que 10 millones estaban desocupados y unos 48 millones en condición de inactivos. Sin embargo, al mismo tiempo, unos 49 millones de jóvenes se encontraban estudiando (básica o post básica) lo cual -únicamente considerando estas dos variables- genera diversas situaciones. Así, los jóvenes que estudian y trabajan representan 13 millones, los inactivos que estudian son 32 millones y los desempleados que estudian son cuatro millones. Desde otro punto de vista, los que trabajan y no estudian son 35 millones, los desempleados que no estudian seis millones y los inactivos que no estudian 16 millones. Si se suma a estos dos 
últimos grupos, se obtiene que los jóvenes que no estudian ni trabajan son 22 millones, lo cual representa alrededor del 21\% del total de jóvenes que hay en la región"11.

En el contexto latinoamericano, según la OIT, las tasas de participación laboral de los hombres jóvenes es aún mucho mayor que las tasas de participación de las mujeres jóvenes, por cuanto el grupo de los hombres que "solo trabaja" llega al 63.7\%, mientras que las mujeres de este mismo grupo apenas suma el 36.3\%. Eso mismo ocurre entre los que "estudian y trabajan" (58.2\% son hombres; $41.8 \%$ mujeres). Las mujeres, en cambio, tienen más presencia en el grupo de los que solo estudian (53.8\%) y en el de los que no estudian ni trabajan (72\%). Este factor de género es una reproducción de patrones culturales de tipo patriarcal que aún tienen mucha fuerza en la región, pero también de ello se infiere que las mujeres jóvenes adquieren un papel central en el desarrollo de las nuevas formas de productividad ligadas al espacio de "notrabajo" que se describía antes y que ahora no es solo un factor marginal y residual del modelo productivo.

Esta apreciación es igualmente válida para los jóvenes ubicados en los estratos de menores ingresos en donde se concentra la mayor proporción de jóvenes que, de acuerdo a la encuesta analizada, pertenecen al grupo de los que "no estudian, ni trabajan". En efecto, como puede observarse en el cuadro número 1, el 21.1\% del total de los jóvenes de América Latina están en total desocupación; el 16.2\% se ubican en los tres quintiles más pobres.

Treinta y cinco millones de jóvenes Latinoamericanos y del Caribe están dedicados solamente al trabajo y 13 millones adicionales combinan el trabajo con el estudio; el $62 \%$ de ellos tiene entre 20 y 24 años. Según este mismo estudio las empresas tienden a emplear jóvenes en mayor proporción que la de otros segmentos de la población en edad de trabajar. Varios factores concurren a esa decisión, el principal de los cuales es que a los jóvenes se les paga, en promedio, apenas un 56\% del salario de la de los trabajadores mayores. También es importante el hecho de que su preparación para el trabajo y su sintonía con las nuevas tecnologías de la información y la comunicación, los hace fácilmente adaptables a los cambios en los procesos productivos.

${ }^{11}$ OIT, op. Cit. Páginas 33 y 34. 


\section{Cuadro 1}

ALC: Características de los jóvenes según condición laboral y educativa 2005

(porcentajes)

\begin{tabular}{|l|c|c|c|c|l|}
\hline & Sólo estudia & Sólo trabaja & $\begin{array}{c}\text { Estudia y } \\
\text { trabaja }\end{array}$ & $\begin{array}{c}\text { No estudia } \\
\text { ni trabaja }\end{array}$ & Total \\
\hline Total & 32.8 & 33.5 & 12.6 & 21.1 & 100.0 \\
\hline Hombre & 46.2 & 63.7 & 58.2 & 28.0 & 49.7 \\
Mujer & 53.8 & 36.3 & 41.8 & 72.0 & 50.3 \\
\hline $15-19$ & 79.9 & 31.8 & 58.3 & 43.7 & 53.4 \\
$20-24$ & 20.1 & 68.2 & 41.7 & 56.3 & 46.6 \\
\hline Quintiles & & & & & \\
1 (más pobre) & 6.7 & 5.8 & 1.9 & 6.9 & 21.2 \\
2 & 6.0 & 6.7 & 2.1 & 5.1 & 20.0 \\
3 & 6.0 & 7.2 & 2.2 & 4.2 & 19.7 \\
4 & 5.0 & 7.5 & 2.8 & 3.3 & 19.5 \\
5 (más rico) & 7.6 & 6.4 & 3.4 & 2.3 & 19.7 \\
\hline
\end{tabular}

Fuente: Elaboración OIT en base a procesamiento especial de encuestas de hogares.

Para las empresas esto constituye una ventaja competitiva que reduce sus costos de operación, incrementa su rentabilidad y responde al viraje hacia la flexibilización laboral que en América Latina se ha implementado con particular rigor. Por eso entre los jóvenes es también mayor la frecuencia de rotación como asalariados de empresas de distintas ramas, así como menor el tiempo de vinculación con contrato laboral a una empresa determinada. Es más frecuente su tránsito entre la situación de empleado a la de desempleado, que hacia otras formas de empleo como el desarrollo de actividades por cuenta propia que según el estudio solo acoge al 14\% de los jóvenes entre 14 y 25 años, en comparación con un 32\% de los adultos que dice tomar esa decisión. Más pronunciada es aún la diferencia entre los jóvenes que dicen conformar una empresa (apenas el 2\%) con relación a los adultos que dicen haber emprendido el camino de ser empresarios (7\%). Pero, como registra el estudio de la OIT: "Estudios en países específicos indican que muchas veces los negocios que inician son una respuesta defensiva a la falta de oportunidades laborales y, por tanto, muchos de los que inician negocios lo hacen por necesidad de ingresos y no por haber detecta- 
do una oportunidad empresarial. En consecuencia, un gran porcentaje de jóvenes que inician un negocio fracasan luego de unos meses en el mercado"12.

La precariedad del trabajo que se ofrece a los jóvenes es patente en las cifras que ofrece la citada investigación de la OIT en donde además se destaca que el 63\% de los jóvenes que trabajan carecen de un contrato. Solo un $24 \%$ de los jóvenes cuentan con un contrato permanente y un $13 \%$ tienen contratos temporales.

En el ámbito rural estas modalidades contractuales son todavía más extendidas: el 84\% de los jóvenes asalariados no tienen contrato laboral y solo un $10 \%$ tiene contrato permanente. En el nivel general, las mujeres jóvenes aparecen como las que cuentan con un mayor porcentaje de contratos permanentes (30\%) y temporales (15\%), pero el estudio aclara que un $15.7 \%$ de ellas se desempeñan como trabajadoras domésticas y que este es su empleo más frecuente.

Otros datos son también muy interesantes en lo referido al tipo de empleo al que acceden: Dos de cada tres jóvenes trabajan en actividades informales, en donde las condiciones de remuneración son bastante reducidas e inseguras. Obsérvese que el ingreso de los jóvenes urbanos se reduce a casi la mitad (54\%) del que perciben los adultos de las ciudades y téngase en cuenta que en las actividades informales generalmente el ingreso es inferior a un salario mínimo. Además, tan solo un 33\% de los jóvenes tiene cobertura de seguridad en salud y un $28 \%$ es cotizante en pensiones. El nivel de sindicalización de los jóvenes apenas si llega al 7\%. Todos estos indicadores están por debajo de los niveles (también precarios) que alcanzan los adultos, aunque ahora la tendencia que ha impuesto la radicalización de la flexibilización laboral es que haya una nivelación por lo bajo de estos factores, lo que va a llevar a una homologación de la situación de los adultos con los muy bajos índices que sufren los jóvenes.

El mayor impacto del "trabajo familiar no remunerado (TFNR)” en los jóvenes ratifica que este sector es en donde se agencian más rápidamente los procesos de aproximación entre la producción y la vida íntegra. Que un $13.5 \%$ de la fuerza laboral de los jóvenes (solo un 4\% en los adultos) haga parte de este segmento ambiguo y des-regulado en donde se generan valores agregados de gran importancia y, sin embargo, no se les asigne salario o remuneración alguna, da un indicio de los espacios de productividad ajenos a la empresa convencional y en los que se desarrolla la impronta del intelecto general. Esto, combinado con la tradición y formas pre-modernas de producción, conducen a que más de la tercera parte (38\%) de la fuerza laboral de los jóvenes campesinos estén sometidos a esta condición.

Una particular preocupación genera el segmento de jóvenes que declara no estar vinculado ni al sistema escolar ni al laboral. Este numeroso grupo está conformado en América Latina y el Caribe por 22 millones de jóvenes, según el referido estudio de la OIT; de ellos el 72\% son mujeres y

${ }^{12}$ OIT. Op.cit. Página 36. 
el 56\% tienen entre 20 y 24 años de edad. Más del 80\% de esta población reside en las ciudades y, de no encontrar una proyección hacia lo público o lograr conectarse a procesos autónomos que se potencian alrededor de actividades cognitivas, lingüísticas, de la información, o del trabajo afectivo, son el caldo de cultivo para que medren otras fuerzas, vinculadas a la violencia o al resentimiento. Para muchos de ellos la deserción escolar es, más que el fracaso en el ciclo formativo, la vulneración del derecho fundamental a una educación universal y de calidad. Para otros es la negación de acceso al derecho a un trabajo digno y la ratificación de la falta de oportunidades que les ofrece la sociedad para el despliegue de su productividad.

A este respecto se percibe una cierta esquizofrenia de las sociedades latinoamericanas puesto que han invertido un importante esfuerzo en la formación de sus jóvenes (este sector de la población acumula el 31\% del total de años de educación de la región) y les han acercado, con mayor eficacia que a otros segmentos poblacionales, a las tecnologías informáticas (los jóvenes cuentan con más del $40 \%$ del total de acceso a estas tecnologías), pero en la distribución de los activos laborales se les asignan porciones gravemente deficitarias, pues solo se les ofrece el $20 \%$ de las oportunidades de empleo y apenas perciben el $10 \%$ de los ingresos laborales. Aunque sea solamente visto desde la óptica de la eficiencia del sistema esto ya trae consigo significativas pérdidas, pues como señaló otro informe de la OIT en el 2004:"Si se redujera a la mitad el desempleo de los jóvenes, la producción de la región crecería entre 4.9 y 7.8 puntos porcentuales adicionales”"13.

En todo caso, se hace indispensable ahondar en las tendencias que se están forjando al interior del grupo de los “jóvenes inactivos”, al igual que en la franja de los desocupados. Nótese que aunque estos dos sectores no son para nada homogéneos, a su interior se cocinan elementos coherentes con las grandes transformaciones que se viven en las formas de trabajo y que se describieron en apartados anteriores. Véase como ejemplo el creciente número de personas que han renunciado a continuar buscando trabajo ante la evidencia de la enorme dificultad para encontrar empleo (el número de semanas que dura una persona buscando trabajo en América Latina y el Caribe ha aumentado). En el caso colombiano, por ejemplo, se muestra como casi la mitad de los hombres jóvenes inactivos (46.7\%) señalan que han transcurrido entre 1 y 5 años desde que abandonaron el último trabajo. El 53\% dice que ha transcurrido menos de un año desde ese evento. En el caso de las mujeres jóvenes, quienes han permanecido temporadas más prolongadas fuera del trabajo (entre 1 y 5 años) son un núcleo aún mayor (58.4\%). Entre estas mujeres ha aumentado el número de quienes no estudian, ni trabajan ${ }^{14}$ (gráfica número 2, página siguiente).

\footnotetext{
${ }^{13}$ OIT. “Global employment trends for youth”. Ginebra, 2004.Citado por OIT. “Trabajo decente y juventud”. Op. Cit. Página 52.

${ }^{14}$ Un estudio del Centro de Investigaciones para el Desarrollo (CID) de la Universidad Nacional calculó en 1,5 millones de jóvenes (el 16 por ciento de la población joven del país) los que en el año 2006 no estudiaban, trabajaban, ni buscaban empleo. Ministerio de Protección Social. CID. Universidad Nacional de Colombia. Bogotá 2008.
} 


\section{Gráfica 2 \\ Colombia}

\section{Distribución de la población inactiva por tiempo desde que abandonó el último trabajo, según sexo. Total Nacional, trimestre enero - marzo de 2009}

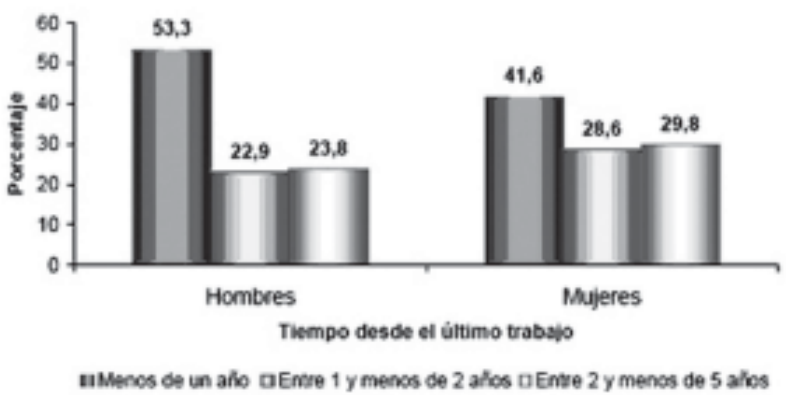

Fuente: DANE - GEIH

En esta realidad empírica se divisa un traslape de situaciones y acontecimientos que atraviesan el mundo juvenil y el universo del trabajo. De un lado están involucrados los procesos de reestructuración del capital que repelen la creación de trabajo bien remunerado, estable y con cumplimiento de derechos y normas que habían sido conquistados en etapas anteriores por parte de los trabajadores. La oferta de empleo se contrae haciendo crecer por encima de los límites habituales el ejército de reserva de desempleados, lo que tira hacia la baja los salarios en el sinuoso mercado laboral. Los empresarios prefieren apostar duro a la flexibilidad, la desregulación y la movilidad de la fuerza de trabajo.

De otro lado, los “inactivos” están mostrando el desaliento de muchos trabajadores frente a las formas tradicionales de empleo; han aprovechado las dificultades adicionales y los abusos con que se ha implantado la reingeniería del capital para tomar distancia de la fábrica, de la empresa que mantiene rezagos tayloristas, de las administraciones de encierro con las que aún se intenta controlar a la fuerza de trabajo en el llamado mundo formal del empleo. Entonces muchos migran hacia otras formas de trabajo, se rebuscan la subsistencia por fuera del empleo formal y encuentran relaciones significativas en el encuentro entre los nuevos modos de laborar y los espacios vitales de la socialización. Se va cambiando el anclaje que ataba inevitablemente el trabajo con la permanencia en una unidad productiva capitalista y asimilaba el empleo con la ubicación en un puesto fijo de producción. Los imaginarios sobre la labor, el trabajo dependiente, la identificación con una determinada ética del trabajo, comienzan un movimiento de mutación 
que todavía no se percibe con claridad, que no se sabe cuanto va a durar, ni en que estructuras más definidas va a derivar.

\section{Las nuevas formas de trabajo implícitas en la informalidad laboral de los jóvenes}

Para el caso colombiano, de los 3.943.000 jóvenes ocupados en Marzo del año 2009 (un poco menos de la cuarta parte de toda la población ocupada a nivel nacional) un 30\% son trabajadores por cuenta propia (un rubro que cubre los más diversos tipos de informalidad laboral) y un $10.6 \%$ son trabajadores familiares sin remuneración ${ }^{15}$. Entre los jóvenes ocupados, la principal posición ocupacional sigue siendo la de obrero o empleado de empresa privada (46.4\%); las demás posiciones representaron el 12.9\% de esta población.

Son muy significativas estas tendencias pues, como se puede observar en la gráfica número 3 , todas las posiciones ocupacionales referidas a formas de trabajo tradicional disminuyeron en su participación en el empleo. Así, la variación entre el 2008 y el 2009 (en las cifras del trimestre Enero-Marzo) fue negativa para la categoría “obrero o empleado particular (-0.6\%); la categoría “jornalero o peón” se derrumbó en un porcentaje cercano al 20\%; la posición “empleado doméstico” cayó en un 8\% y la categoría “obrero o empleado del gobierno” disminuyó en un 4.8\%.

En cambio las posiciones del empleo informal, captaron una mayor proporción de los trabajadores jóvenes, marcando una tendencia de expansión que parece consolidarse: la categoría "trabajadores sin remuneración” creció el 23.6\%; los “trabajadores por cuenta propia” se incrementaron en $7.5 \%$ y apareció la categoría “otros” que, aunque es aún pequeña e imprecisa (para dar cabida a formas de trabajo nuevas que no habían sido clasificadas), registró un crecimiento del 248.5\%. Una indagación particular merece el incremento de la categoría “patrón o empleador” (50.3\%), que representa algo más del 1\% del empleo joven, pues esta posición de emprendedor empresarial es "rara avis" 16 en el mundo juvenil.

\footnotetext{
${ }^{15}$ Se considera un "trabajador sin remuneración” en Colombia a todo aquel que en la Gran Encuesta Integrada de Hogares del DANE contesta afirmativamente a la pregunta: ¿Trabajó la semana pasada en un negocio familiar por una hora o más sin que le pagaran? Por su parte, el trabajador por cuenta propia hace parte de los grupos de trabajadores que, según la definición del DANE para la Encuesta Nacional de Hogares, se consideran del sector informal. Hace parte de empresas con 10 o menos trabajadores y no son ni profesionales ni técnicos. Ambas categorías son empleo de muy baja calidad, con remuneraciones precarias, $\mathrm{y}$, generalmente, con baja cobertura en seguridad social.

${ }^{16}$ rara avis f. Expresión latina que significa 'ave rara' y se aplica a personas o cosas que se encuentran raramente.// Extraño, Extraordinario. Maria Moliner. Diccionario de uso del español. Editorial Gredos. Madrid. 2007. Página 2484.
} 


\section{Gráfica 3}

\section{Colombia}

\section{Distribución porcentual y variación de la población ocupada de 14 a 26 años, según posición ocupacional. Total Nacional, enero - marzo de 2009}

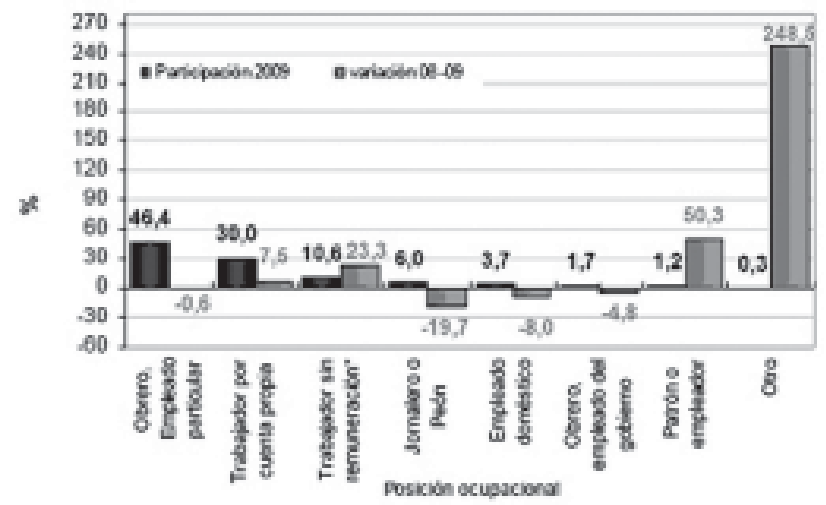

Fuente: DANE - Gran Encuesta Integrada de Hogares - GEIH.

* Incluye a Trabajador familiar sin remuneración y a los trabajadores sin remuneración en empresas de otros hogares.

Nota: según la Clasificación Internacional de la Situación en el Empleo - CISE 83, de la Organización Internacional del Trabajo - OIT. la categoría “Otro” incluye a las Personas no clasificables por categoría en el empleo.

No hay que olvidar que la Encuesta que se usa en este trabajo solo mide la "percepción" de empleo y por tanto no está ofreciendo datos exactos de la relación entre la Población Económicamente Activa y el empleo efectivo entre los jóvenes y que si se analizan las tendencias críticas de la economía del país, la situación objetiva de desempleo y subempleo (desempleo oculto) puede ser todavía más aguda ${ }^{17}$.

Todo el aparato económico hegemónico ha virado hacia las ramas de actividad del sector terciario, servicios personales, de información y financieros. Para el caso de los jóvenes estos se ve reflejado en los sectores que los emplean. Nótese que, según el DANE y como puede apreciarse en la Gráfica número 4, la mayor proporción de población ocupada entre 14 y 26 años, en las ciudades, fueron: comercio, hoteles y restaurantes (26,6\%),

\footnotetext{
${ }^{17}$ En el nivel nacional y para toda la Población Colombiana en edad de trabajar, si se suman el desempleo más el subempleo (objetivo y subjetivo), se llega a una cifra de $43 \%$ que representa el desempleo abierto más el desempleo oculto.
} 
y servicios comunales, sociales y personales (15,9\%). La industria manufacturera apenas proveyó el 13,0\% del empleo joven; las demás ramas de actividad concentraban el 22,6\%. En el sector rural la agricultura, ganadería, pesca, caza y silvicultura ocuparon el $21,7 \%$ del total del empleo juvenil en el país.

\section{Gráfica 4 \\ Colombia}

\section{Distribución porcentual y variación de la población ocupada de 14 a 26 años, según rama de actividad. Total Nacional, enero - marzo 2009}

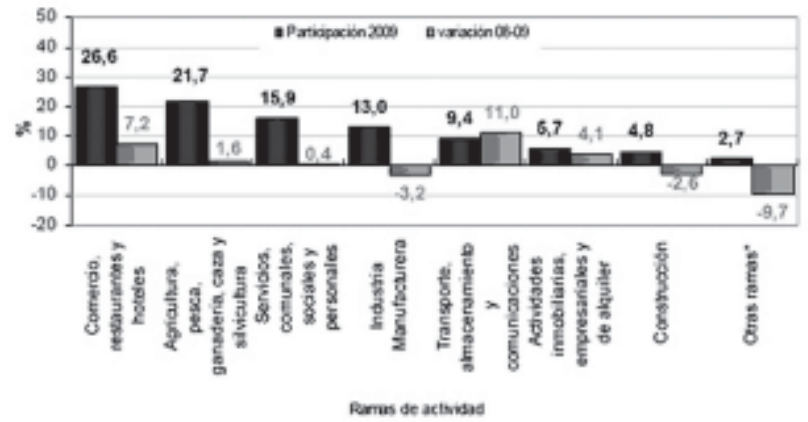

Fuente: DANE - Gran Encuesta Integrada de Hogares - GEIH.

Otras ramas: exploatción de minas y canteras, Suministro de electricidad, gas y agua e intermediación financiera

Es de destacar, según el mismo informe, que las ramas convencionales de la producción vieron caer la generación de empleo para los jóvenes de 14 a 26 años con respecto al trimestre móvil enero-marzo de 2008 así, la industria manufacturera disminuyó en 17 mil personas (-3,2\%), “otras ramas” registró una caída de 11 mil personas (-9,7\%), seguido de la categoría construcción, rama que registró una caída de 5 mil personas (-2,6\%). Estos cambios generalmente van asociados a niveles más precarios de las condiciones del empleo de los jóvenes.

\section{Implicaciones, para las iniciativas productivas de los jóvenes y para el desarrollo, de la re-socialización del trabajo y el no- trabajo}

La transformación del trabajo también se manifiesta en que esa cada vez más importante franja de jóvenes y adultos sumidos en el desempleo, 
afecta el conjunto de las formas de producción y de las modalidades para acceder al consumo y exige de un esfuerzo creativo para la sobrevivencia por parte de millones de personas, a partir del cual se genera y amplía un sector novedoso y liminal de la reproducción económica que bien pude denominarse espacio de la socio-economía.

En este campo social han confluido todos estos jóvenes que las estadísticas registran como desempleados, subempleados o (parte de los) inactivos, que para las nociones de la economía tradicional, simplemente "no trabajan" pero que entablan relaciones sociales productivas, practican intensamente su condición de urbanitas que piensan y constituyen territorios propios y que, exceptuando su falta de acceso a un salario regular, han desarrollado similares potencias cognitivas y lingüísticas, así como la capacidad de pertenecer a redes, que sus pares asalariados. Es decir, los "sin trabajo" son seres productivos que indagan sobre formas de organización adecuadas y viables en donde sea posible redefinir la relación entre la vida y la producción, y, por extensión la configuración social de un nuevo territorio productivo que abarque el trabajo y el "no trabajo".

Son las formas del trabajo y su relación con el tiempo las que se han desplazado de manera contundente. Hoy existen miles trabajadores dispersos, des-asalariados, navegando en el mundo del intelecto general y cuyos ritmos y secuencias productivas se mueven en ondulaciones totalmente diferenciadas de las que son propias de la fábrica fordista. Como se ha dicho antes, los jóvenes habitantes del trabajo re-socializado no permanecen en ningún puesto fijo, muchas veces hacen parte de varias actividades productivas a la vez, proliferan en el empleo por cuenta propia y, sin mucha resistencia se adaptan a escenarios de producción en donde las fronteras entre la vida y el trabajo se han opacado.

Para los jóvenes la carencia de salario o su indeterminación (éste puede ser fluctuante, recibido en períodos irregulares, en proporción inversa a su contribución a la creación de valores agregados) no es la única dimensión de la reestructuración que les afecta; desde otro plano, igualmente les facilita mantenerse en contacto con mayores oportunidades de acceso a técnicas y conocimientos productivos diversos y multiplica su posibilidad para integrarse a múltiples redes. En esa atmósfera también han conseguido que los afectos, las formas estéticas de apropiación del territorio, las subjetividades de cooperación y proximidad, así como su inmensa capacidad para crear imágenes y símbolos, sean no solo elementos de la vida del no- trabajo, sino que vayan siendo dotados de facultades directamente productivas. Por eso su aptitud para inscribirse en la amalgama que ahora se presenta entre la creación de los medios necesarios para la vida en la sociedad y la producción de la vida misma. Los jóvenes han demostrado particular destreza para transformar en medios de vida lo que hasta hace poco era tan solo actividad ociosa o encuentro cultural y han aprendido a evadir ciertos circuitos del mercado, a interceptar otros o a reinventar prácticas de mercado social como el trueque para garantizar la sobrevivencia en entornos de transición y crisis como los que hoy los arrojan a la pobreza. 
De esta creciente complejidad en la contextura del trabajo al que se están vinculando aceleradamente los jóvenes, germinan sistemas y organizaciones caracterizados por la singularidad y la diversidad, que contribuyen a convertir la construcción de lo público y lo común en un conjunto abierto de redes que se diferencian de los ordenamientos jerárquicos y cerrados que distinguieron a las empresas ligadas exclusivamente a los mandamientos del mercado.

La discusión alrededor de esta particular morfología del trabajo, en donde los jóvenes son el sector más dinámico, replantea varias de las premisas aceptadas por décadas acerca del funcionamiento del modo de producción del capitalismo. Tal vez la más importante es la referida a la ley del valor enunciada por Marx en el siglo XIX y a través de la cual se han establecido las metodologías de medición del costo y la remuneración del trabajo. El reto para la teoría del desarrollo humano es comprender los grandes cambios que se han operado en la dinámica de lo que se concebía como el trabajo socialmente necesario (trabajo abstracto), fuente del valor en general. Se erigen grandes interrogantes sobre, por lo menos, dos cuestiones fundamentales:“¿De qué tiempos de trabajo socialmente necesario podemos hablar allí, cuando los ritmos y los tiempos de producción se han acelerado o simplemente no pueden ser cuantificados con las variables convencionales?, ¿por qué cauces puede apropiarse el capital del plusvalor de formas de producción que discurren por fuera del sistema salarial?, ¿cómo encaja en el paradigma del valor- trabajo marxista el producto de formas asociativas, cooperativas o comunales cuyos productores generan simples valores de uso para su propia subsistencia y cuya resistencia radica, justamente, en retirarse de las redes duras del mercado capitalista y dar a la luz otras redes de intercambio?(...) El segundo asunto en cuestión, hace relación a la naturaleza de la masa de desempleados que estructuralmente genera el modelo de capitalismo en curso, y a la población en situación de pobreza e indigencia, en medio de unas políticas socio- económicas que agudizan la propensión a un incremento de ella y a que se consolide, claramente, como la condición predominante en este tipo de desarrollo", ${ }^{18}$

Hay entonces que profundizar en el debate sobre la metamorfosis que ha sufrido el proceso de valorización inherente a la producción capitalista y cómo se entroncan allí las formas de producción comunitaria, así como todos los sectores que van quedando al margen del mercado institucionalizado, en donde se han instalado los nuevos campos de valorización y de productividad. El principal afluente de estos nuevos espacios para la generación de valor- trabajo social es el universo del desempleo, del no- trabajo, de la llamada "informalidad” (subempleo) y del trabajo no remunerado. Esto viene quebrando el aceptado paradigma según el cual existe una división social entre trabajadores y desempleados que sería una forma de alimentar la permanente búsqueda de una mayor extracción de plusvalor a la población que representa el trabajo necesario (indispensa-

${ }^{18}$ Oscar Useche, Los Nuevos sentidos del desarrollo. Op.cit. “ Páginas 21 y 22. 
ble) para el funcionamiento del sistema productivo. La población desempleada o población que no trabaja representa, en esta visión, un excedente de capacidad viva de trabajo a la espera de que su excedente (plustrabajo) sea valorizada para el capital. El trabajo no empleado sería nada menos que una superpoblación relativa dueña de trabajo vivo, pero superfluo para el capital en un momento dado; esto es un ejército disponible de reserva que sirve para sostener los salarios a la baja (al trabajador que no le sea aceptable la remuneración, se le tienen varios candidatos a relevarlo de manera inmediata) y un acicate permanente para la elevación de la productividad del trabajo.

Este segmento de trabajadores "libres" en el capitalismo fabril que no va ser pagado por el fondo de trabajo de los capitalistas pues se queda a la espera de ser contratado, a falta de un salario, queda al margen de la producción y a expensas de políticas paliativas asumidas por la sociedad y el Estado que los tratarán ya no como trabajadores sino como pobres o indigentes. La pobreza se convierte así, durante esta prolongada fase del capital, en su propia ley de población y se presenta, paradójicamente, como resultado del incremento y la extensión de la fuerza productiva del trabajo. En los Grundrisse, Marx acota al respecto:"Si ocurre que el capitalista no necesita del plustrabajo del obrero, éste no puede realizar su trabajo necesario, producir su medios de subsistencia...no solo como privados de recursos, sino como incapaces de apropiarse de los medios de subsistencia por medio del trabajo, en consecuencia como paupers” (...) Si ésta (la población excedente) es mantenida, no lo es a costa del fondo de trabajo sino del rédito de todas las clases. Lo cual ya no ocurre gracias al trabajo de la capacidad laboral misma, merced a la reproducción normal en calidad de obrero sino que lo mantienen otros por compasión, en cuanto ser viviente; por lo tanto se convierte en zarrapastroso y pauper; al no mantenerse ya mediante su trabajo necesario, esto es, gracias a su intercambio con una parte del capital, queda excluido de las condiciones de la relación de intercambio e independencia aparentes”. ${ }^{19}$

Pero acontece que estas conclusiones de la investigación marxista ya no alcanzan a explicar la diversidad de formas productivas que se cuecen en la trasescena de los desempleados o de los no-trabajadores. Ha retomado vida el potencial productivo de esa legión de desconectados de las empresas formalizadas y del mercado, el sistema salarial ha dejado de ser el único determinante de las relaciones de trabajo y ya la única opción para allegar medios de vida no es la ayuda pública o el recurso de la caridad (aunque muchos se vean obligados a seguir recurriendo a estos procedimientos).

La teoría del trabajo debe entonces evolucionar y eso se refleja en la interpretación sobre las mutaciones que se advierten en el mundo del trabajo y del no- trabajo juvenil, tan entrelazados ahora. El hecho es que los

${ }^{19}$ Carlos Marx “Elementos para una crítica...” Op. Cit. Páginas 111 y 117. 
jóvenes brillan por su iniciativa para hacer uso del conocimiento social acumulado; se sumergen fácilmente en los resquicios del trabajo inmaterial y afectivo, bucean en busca de comprender y acercarse a los saberes ancestrales, se preguntan por su papel en la defensa del planeta y en el manejo de la nueva riqueza global representada en las fuentes de agua, en el oxígeno, en la biomasa de las cuales son ricos nuestros territorios y, muchas veces sin proponérselo, se aproximan a las fuerzas más determinantes de la producción social global.

Los proyectos productivos de los jóvenes pueden entenderse desde la potencia de lo común, es decir de la progresiva comunalidad del trabajo. Los sujetos de estas nuevas prácticas productivas ya no son meros agentes económicos en tanto: "Actúan productivamente cada vez menos escindidos de sus singularidades sociales, de su historia, de sus valores, de sus instituciones y su cultura, y por consiguiente, tienden a incorporarse como sujetos activos portadores de subjetividades sociales, cuyo principal valor agregado es la producción global de la vida social. Estas expresiones no se dan de manera única y pura; se intercalan y conectan con los circuitos de la economía de mercado y con el Estado, se tocan y repelen, son influidas por estos factores dominantes y generan antagonismos no conocidos". ${ }^{20}$

Esto fomenta entre los jóvenes acuerdos productivos de carácter voluntario cuyo único motor no es la ganancia, la utilidad personal; cobran fuerza, en cambio, actitudes cooperativas y cívicas propicias para la difusión de las libertades y las potencias humanas y para la valorización de los afectos; es en todo sentido una producción centrada en el trabajo inmaterial y afectivo. Así lo describe Hernán Camilo, un joven dirigente de una iniciativa ecológica: "La cosa es, ¿qué producimos nosotros?: además de algo tangible, que se pueda ver; producimos conciencia. Es tan sencillo como una actividad, un semillero, vamos a producirle a los niños, aparte del producto que nos genera la tierra, vamos a producir a la gente una conciencia sobre la tierra. Y comenzamos a producir una cadena también: que de pronto te concientizas tanto de no botar el papel a la calle que cuando estás conmigo no lo botas, y cuando en otro grupo haces que ese grupo no lo bote también. Esa producción de sentimientos, de sentir la tierra, de todo lo más mínimo puede estar ligada a producir algo. A producir sonrisas, entonces tenemos titiriteros, malabaristas. Todo llevado a lo lúdico, porque no podemos entrar a la gente: oiga, venga, la ecología es esto y esto. No. Hay que entrarle a la gente como a nosotros nos gusta que nos entren. Producir sonrisas, producir sensibilidad a la gente. Eso, hasta en su más mínima expresión, estamos produciendo algo". ${ }^{21}$

Otro problema para las iniciativas productivas de los jóvenes es que todas estas oportunidades se generan en un contexto de globalización co-

\footnotetext{
${ }^{20}$ Oscar Useche. “Desarrollo, ciudadanía...” Op.cit. Página 59.

${ }^{21}$ Entrevista a Hernán Camilo Quintero. Iniciativa Productiva Agroecológica. Banco de Datos. CEIHS. Uniminuto. Bogotá. 2008.
} 
mandado por un modelo y unas tremendas fuerzas centrífugas que se han apropiado de las innovaciones y mantienen un control absoluto del mercado y de los procesos comunicativos trasnacionales.

Los jóvenes y otras fuerzas del cambio se han replegado en las comunidades locales y en los grupos de población específicos desde donde han desarrollado su vocación minoritaria, o sea el abandono de toda pretensión de copar lugares del poder de centro. Desde esta posición están replanteando el propio significado de lo comunal y lo comunitario, así como las posibilidades y los límites de su autonomía.

En la esfera de lo productivo enderezan sus preocupaciones hacia la construcción de capacidades propias para integrarse al circuito de producción cognitiva, para apropiarse, adaptar y transformar las nuevas tecnologías y para generar sistemas productivos alternativos con base en maneras originales y creativas de cooperación social del trabajo y de gestión de los recursos.

El otro dominio en donde han de incursionar las iniciativas productivas juveniles es en el del intercambio, la circulación y la distribución de bienes y servicios; tres direcciones han de ser evaluadas y abordadas para constituir campos de fuerza en este ámbito:

- Remozar y resignificar espacios de intercambio por fuera de la dominación mercantil y de las prácticas de consumo regidas por el beneficio individual. Un ejemplo es la Intensificación de los ejercicios de trueque en donde se conectan procesos productivos de diversa naturaleza y diferente producto, de tal manera que se someten a intercambio valores sociales de uso y se subordina la consideración del valor de cambio que ellos tienen el mercado de consumo.

- Fortalecer, estudiar y perfeccionar el emplazamiento de mercados sociales que buscan una redistribución más equitativa para los productores directos, en donde se minimiza la intermediación y se fijan precios más cercanos al valor de los productos, a partir de estrategias que superen la relación costo- beneficio monetario y reflejen e integren el esfuerzo de todos.

- Crear capacidades para establecer relaciones e interpelar los circuitos del gran mercado capitalista sin ser subsumidos y arrasados por él. Esto pasa por impulsar movimientos que busquen poner límites sociales al mercado, exigir responsabilidad social de los grandes productores, financistas y comerciantes y promover el respeto a los derechos de los consumidores. A la par, impulsar formas de consumo responsable y una crítica permanente al individualismo posesivo y a la alienación proveniente del consumismo.

Como dicen los teóricos de la economía social, este proyecto: “produce sociedad y no sólo utilidades económicas, porque genera valores de 
uso para satisfacer necesidades de los mismos productores o de sus comunidades -generalmente de base territorial, étnica, social o cultural- y no está orientada por la ganancia y la acumulación de capital sin límites. Porque vuelve a unir producción y reproducción, al producir para satisfacer de manera más directa y mejor las necesidades acordadas como legítimas por la misma sociedad". ${ }^{22}$

A estos fenómenos es a los que hay que atender, antes que continuar en las penumbras de políticas públicas en materia social por medio de las cuales el Estado a menudo se reduce a mantener dentro de límites soportables la pobreza estructural que el sistema reproduce mediante las medidas asistenciales. La sociedad entera debería atisbar en estas figuras que emergen como semillas de nuevas formas de vivir y que propician la constitución de vínculos sociales relacionales en torno a la producción de satisfactores integrales de las necesidades materiales, culturales y sociales, así como de la recuperación de los derechos de todos. Tal vez así pueda abrirse otra senda al desarrollo humano.

${ }^{22}$ José Luis Coraggio, "De la redistribución del ingreso al desarrollo de una economía social". 


\section{Bibliografía}

Coraggio, José Luis (2002), “De la redistribución del ingreso al desarrollo de una economía social”. Ponencia presentada en el Encuentro: "Hacia el Plan Fénix. De la crisis actual al crecimiento con equidad”. Facultad de Ciencias Económicas de la Universidad de Buenos Aires.

DANE. Departamento Administrativo Nacional de Estadística (2009), Gran Encuesta Integrada de Hogares. Colombia. 2008-2009

Marx, Karl (2002), Elementos fundamentales para la crítica de la economía política. (Grundrisse) 1857- 1858. Volumen 2. Siglo XXI Editores. México.

Moliner, Maria (2007), Diccionario de uso del español. Editorial Gredos. Madrid.

Oficina Internacional del Trabajo (OIT) (2007), Trabajo decente y juventud. Lima.

Idem (2004), Global employment trends for youth. Ginebra.

Useche, Óscar (2008), Los Nuevos Sentidos del Desarrollo. Universidad Bolivariana. Santiago.

Useche, Óscar et. al. (2007), Desarrollo, ciudadanía y cambio social. Uniminuto - DANSOCIAL - Fundación Carolina. Bogotá.

Virno, Paolo (2003), Gramática de la multitud. Ediciones Colihue. Buenos Aires.

Idem (2004), “Crear una nueva esfera pública sin Estado”. Entrevista por Hector Pavón en El Clarín. 24.12.2004. Buenos Aires. 